\title{
The Impact of Applying the Total Quality Management and Kaizen Methods on the Maintenance of Electricity and Water sectors
}

\author{
Salloom A. Al-Juboori \\ Professor in Mechanical and Systems Eng. (PhD, M.Sc Leeds Uni. U.K, \\ B.Sc Baghdad Uni.), Head of Industrial Systems Engineering Department/ \\ Engineering Faculty/ Mutah University/ Jordan
}

Fawaz A. Al-Azemi, M.Sc

doi: 10.19044/esj.2016.v12n24p212 URL:http://dx.doi.org/10.19044/esj.2016.v12n24p212

\begin{abstract}
In this work the total quality management (TQM) and Kaizen philosophies were applied on the electricity and public water sector maintenance. The methodology of collecting the data was by designing a special questionnaire containing a series of questions comparing these two philosophies for a specific period of application to study their effect on the maintenance and the cost in the electricity and public water sector. After six months of applying these philosophies, the questionnaire data were collected and analyzed using SPSS package. The results have shown that $55 \%$ of employees believe that the philosophy of kaizen is relatively applied in the electricity sector. But there is a ratio of $65 \%$ of them think that the administration of the total quality management is the most suitable to be applied in the electricity and water sectors. In addition to that there is a ratio of about $50 \%$ see that both methods have achieved better improvements of maintenance in comparison with traditional methods, consequently both methods were successful in the electricity sector for improving maintenance and reducing the cost. But the results were almost equal and this may indicate that due to the lack of sufficient knowledge of the pros and cons of both ways.
\end{abstract}

Keywords: TQM, Kaizen, SPSS Package, Maintenance, cost

\section{Introduction}

The industrial revolutions and their development increased the competition of many of the new global changes and the freedom of trade and breadth of its size at the level of the whole world. The wide spread of 
markets global and orientation are all for the adoption of standard specifications, which has forced many organizations seeking excellence and innovation in the fields in front of the option of providing global products and widespread to meet international standards through attention to its human resources (Hongyi, 2002). The search for excellence and creating opportunities for creators forced to ask ideas and to take advantage of them in addition to respond for the needs and desires of customer's reliance on the concept of quality management. It is clearly in order to progress and access to the means of helping and achieving the best performance by increasing the operational capacity and enhance the competitiveness of local and global, that is to achieve this and more help to increase the volume of sales and profits curve. Khan, 2006, has mentioned that there is a stiff competition taking place in the sector of production and services in addition to the diversity of methods and techniques used, and also accelerates the movement of change in unprecedented way, which makes the company or institution in the case of research and the pursuit of lasting to ensure a place in the market and the scope of work.

The movement of changes become accompaniment to all kinds of services and sectors and also on all levels, whether large enterprises, small and medium. This led to the emergence of several concepts accompaniment to this atmosphere of competition, and these concepts constitute a means of entry and continuity in the world of competition strongly, which in the case of application and taken as the basis fixed in the deal to ensure the company's stability and progress. The concepts were to be on the companies to ensure the concept of TQM and now thanks to the vast amount of information and communication technologies which are a characteristic of the modern data thought practical and scientific management, especially contemporary contributed significantly to the development of the structure of economic organizations dramatically, it cannot be achieved only through the application of the concept of TQM (Saman, 2010). The quality became one of the most important principles of management at the present time, where the administration previously was based on the principle that the success of the company means manufacturing products and providing services faster, cheaper and discharged into the markets, and the provision of services for those products after selling them in order not to show the defects are apparent (Tauseef, 2012).

It is then followed by a series of theories and management practices and comprehensive studies and non-inclusive, which stresses the quality that has made some companies to develop and expand the concept of quality management by making management strategy and adding aspects of more comprehensive sophisticated methods in the field of quality improvement. Dealing with customers and suppliers preference will improve the methods 
of quality assurance to become the method of censorship strategically quality strategy and notes that TQM is an extension of the quality management strategy. But TQM will be deeper and more comprehensive than the quality management strategy that crystallized the TQM philosophy general administrative focus on the efficient use of material and human resources of the organization. Satisfying customer needs and achieving the goals of the organization should be in the context of compliance with the requirements of society (Melsa, 2010).

Date of Total Quality Management (TQM) in the beginning as the first event of the term was by the Naval Air Systems Command to describe their approach to the management of the Japanese way to improve quality. It is an umbrella methodology for continuous improve the quality of all operations, it depends on the knowledge of the principles and practices which are (Jack, 1995):-

- $\quad$ The behavioral sciences

- $\quad$ The analysis of quantitative and non-quantitative data

- $\quad$ Economics theories

- $\quad$ Process analysis

\section{Theoretical Framework}

The philosophy of TQM and the philosophy of kaizen are the only way to manage the institutions and to achieve high accuracy in quality in the present and the future. Their application in the electricity sector is the way of successful to ensure product or service quality, it is a way to manage all areas in order to get customer satisfaction. Where are the overall quality and the philosophy of kaizen management, in addition to active participation in the electricity sector and all sectors administration, working to reach a positive outcome in the field of leadership work correctly (Lakhe, 1993).

The theoretical framework in this study will be through personal interview and provide set of questions to the owners of expertise in the field of electricity and water sectors as a case study. This will be through the discussion of all aspects of the philosophies of TQM and Kaizen concerning the overall quality and costs in order to know the strength of each philosophy points and weaknesses in order to reach a theoretical approach detailed, clear-cut and ideas in order to be applied to these sectors. Also this study aims to draw the broad points for the management of quality and access to the best method by which to achieve the high quality of the product and reduce the cost, achieve customer's satisfaction and all management objectives.

The present work methodology is by applying these philosophies for six months, then putting series of questions and presented them to a sample of employees in electricity and water sectors and discussing with them in 
detail to get a clear answer for each question or proposal. Also by detail seminars of TQM and Kaizen philosophies for clients who are dealing with the electricity sector directly and discuss customers questions and listening to their suggestions and their needs. You must surround this nucleus through a commitment to quality, and reporting quality message and the recognition of the need to change the culture of the organization to create a comprehensive quality (Salman, etal, 2010). So, the TQM and Kaizen philosophies application in the electricity and water sectors focuses on the management style at all administrative processes in order to achieve the goals and needs of the beneficiaries and their expectations of services and at the same time to achieve all the objectives of the electricity and water sectors. Also will achieve less cost, through the optimal use of the potential of all employees and to continue the relentless pursuit towards the continuous development of services and goods by using statistical methods, quantitative data and talk constantly to make the organization in the competition situation (Martinez, 2009).

\section{TQM Philosophy}

The concept of total quality management is one of the modern management concepts that expand the concept at the moment and it is noted widespread in various levels and in various sectors. The companies have taken a basic approach to the management application and plan that and aim to improve and develop the performance on an ongoing basis. That is by responding to the requirements of the customers, which are the primary objective of this approach. The specialists in this approach were defined the TQM, depending on the point of view of the importance of such Definitions are (Phu Van, 2011):

- $\quad$ Armand Vijboum "total customer satisfaction."

- $\quad$ Arossbe "conformity with the requirements"

- Joseph Juran, "the accuracy of Use by what he sees as the beneficiary."

- $\quad$ Deming "unexpected degree of consistency dependence fit the market at a low cost."

TQM is a management approaches that rely on focus on quality, based on the participation of the organization, which aims to long-term success and sustainability. It is accessed through customer satisfaction and benefits all members of the organization and the community. In other words, TQM is a comprehensive quality management; it is a way of thinking in achieving the desired objectives, organizations and processes to ensure that things are on the right track. Also it is a thinking process which can change (John, 2003). TQM applies to the total in the overall quality of the organization as a whole management. Therefore, unlike ISO 9000 initiative, 
which may be limited to the production of products for delivery operations? TQM applies to all activity in the organization. Also, unlike ISO 9000, TQM soft covers issues such as ethics, attitudes and culture. And also there are several ways to express the TQM philosophy and there are also many people who had TQM influence them and they are also influenced by and among them (Deming, Juran, Crosby, Feigenbaum, Ishikawa and Imai). The extraction of wisdom from these gurus to eight principles specified in ISO 9000 (Hongyi, 2002). The concept of TQM which includes many of the terms and ideas that came to be one of the types of philosophy, and also there are many principles of comprehensive management, and that are the eight quality management principles which are (Edward, 2002 and Carolin, 1996):

- $\quad$ The customer is the most important element of organizations relies on them, and therefore it must be the most important thing is to understand the current and future customer needs, meet customer requirements and work to find beyond customers - organization focused on customer expectations.

- $\quad$ Leadership - the people who works on the establishment of goals and directions and internal environment of the organization.

- $\quad$ Involve people - people's participation at all levels is the basis of the organization and their full participation enables their abilities to be used for the benefit of the organization.

- $\quad$ Operations approach - is to reach the results that the organization seeks to achieve greater efficiency when administered related resources and activities are managed as a process.

- $\quad$ Administrative systems approach - to identify and understand the principles of the management system of interrelated processes for a particular purpose contributes to the effectiveness and efficiency of the organization.

- Continuous improvement - is a permanent objective of the organization.

- $\quad$ Prevention approach for decision-making - effective decisions based on logical and intuitive analysis of data and information.

- $\quad$ Mutual benefit and supplier relationships - mutually beneficial relationships between the organization and its suppliers enhance the ability of both organizations to create value.

The TQM is an approach taken by the business, in the promotion and activation products and services to private company in order to get full customer satisfaction. In TQM effort, each member of the organization participations in improving processes, services and products and the culture in which they work. It aims to harness the human and material resources (organization) in the most effective way to achieve the organization's goals. By implementing the TQM strategy, the data and the effective 
communications will integrate the quality of discipline in the culture and activities of the organization (Jackueline, 1996 and Thomas, 1995).

\section{Kaizen Philosophy}

It is a method and philosophy devised lead the industrial enterprises, and financial institutions, in order to be applied in a lot of aspects of life, as they generally rely on the analysis and practical. In the field of business or industries, usually indicate the word "kaizen" the activities that lead to continually improve all aspects of the work, such as manufacturing, administrative management, consolidated activities and ways of working (Kai, 2006 and Mihail, etal, 2011). Kaizen is a system that involves every employee - from senior management to the cleaning crew. Also encourages everyone to come up with proposals for a small improvement on a regular basis. This is not a once a month or once a year activity but it is continuous process. Japanese companies such as Toyota and Canon have written for a total of 60 to 70 suggestions per employee per year down, shared and implemented (Gratiela, 2011).

Kaizen is based on making small changes on a regular basis: always improve productivity, safety and efficiency while reducing waste. Also Kaizen is based on changes in any place that improvements can be made. Western philosophy can be summarized as, "If it is not broke, do not fix it". While Kaizen philosophy says that: "do it better, make it better, and improve it even if it is not broken; because if we do not, we cannot compete with those who do not" (Grips, 2009). Kaizen in Japan is a system of improvement which includes both home and business life. Kaizen even includes social activities. It is a concept that is applied in every aspect of the life of the person side. In business kaizen is many components from Japanese companies that have been seen as a part of their success includes, Quality circles, automation, and systems proposal, just in time delivery, Kaizen is included in the framework of kaizen system business management (Koichi, 2011 and Scot, 2004). Also, Kaizen includes the development of standards and then consistently improve those standards to support the highest standards involves kaizen also provides training, materials and supervision of what is needed for employees to achieve the highest standards and maintain its ability to meet those standards on an ongoing basis. Also it can organize a group of kaizen methods into the following categories (Cristinan, 2009 and Jagdeep, 2010):

- Individual versus teamed.

- $\quad$ Day-to-day versus special event.

- $\quad$ Process or value stream level versus sub process level.

Kaizen is a continuous improvement based on some guidelines such as (Thomas, 1995): 
- Good operations bring good results

- $\quad$ Go see for yourself to understand the current situation

- $\quad$ Talk with the data, and management of the facts

- Take action to contain the correct root causes of problems

- Work as a team

- Kaizen is everybody

- $\quad$ And much more

\section{Data Collection}

In this work, the authors will follow a particular approach to achieve the goals that have been mentioned previously and in order to reach a solution to the problem posed by the research in the beginning. So by applying this research to a certain class of society, companies, private institutions and government employees through designing a special questionnaire containing series of questions that will guide them to answer each question according to its competence and specialized in the workplace. Also the questionnaire is distributed to a certain classes of society and these category workers in businesses, administrative, industrial and others, to reach out and see how much and how to achieve things and requirements must be implemented in order to provide a good level of services provided to the clients and to meet all its needs due to the application of these two methods philosophies. Also the aim of this questionnaire is to compare between the application of TQM and the kaizen philosophies and to see which ones have the best positive impact. The results of the study also applied in the currency and better knowledge of the pros and cons of them in order to reach the best results.

\section{Statistical Analysis}

The distribution of the study sample by gender is as shown in table (1) and Figure (1).

Gender
Male
Female
Total

Table-1 Distribution of the study by gender Number

15

5

20

Percentage
$75 \%$
$5 \%$
$100 \%$

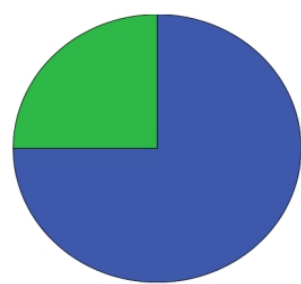

昆品

Fig-1 Distribution of the study by gender 
Table- 1 and Fig- 1 show that the distribution of the study sample by gender, where it can be noted that the male makes up the largest proportion of the study sample rate which is about $75 \%$ compared to the proportion $25 \%$ for females. And this shows that the male category constitutes the largest number of employees of the electricity and water sectors. While the distribution of the study sample by qualification as shown in table-2 and Fig2.

Table-2 Distribution of the study by qualification

Qualification
Diploma
BCs
High Diploma
Master
PH.D

Number
0
14
1
3
2

Percentage
$0 \%$
$70 \%$
$5 \%$
$15 \%$
$10 \%$

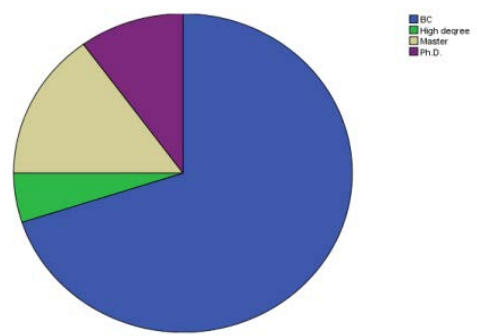

Fig-2 Distribution of the study by qualification

The distribution of the study sample according qualification shows that those who are schooled bachelor makes up the largest proportion of the study sample at a rate of $70 \%$ and the lowest rate was for Diploma $0 \%$, and either doctorate came by $10 \%$ and higher diploma by $5 \%$. The distribution of the study sample by age is shown in table- 3 and Fig-3.

Gender
$20-40$
$40-60$
$60-80$
Table-3 Distribution of the study by age

\section{Number}

17

3

0

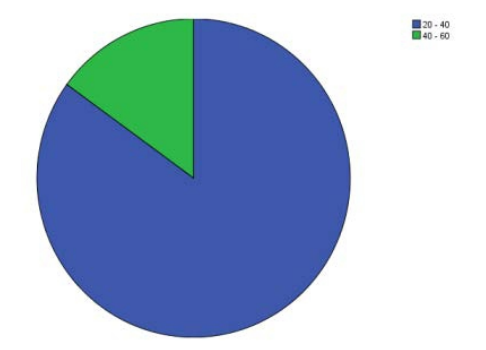

Fig.3 Distribution of the study by age
Percentage

$85 \%$

$15 \%$

$0 \%$ 
It is clear from the distribution of the study sample by age, is that those aged 20 to 40 makes up the largest proportion of the study sample at a rate $(85 \%)$ and the lowest rate was those aged from 60 to 80 by $(0 \%)$. The collected data were statistically analyzed, the level of significant was chosen of $\alpha=5 \%$ and here are sample of the questionnaire's questions analysis were selected as shown in tables 3 to 6 . These tables show the question number which has been answered by the respondents, number of respondents, the mean value, the standard deviation, the calculated t-value, degree of freedom and the statistical significant.

Table- 4 Statistical Analysis of questions 18 and 19

\begin{tabular}{|c|c|c|c|c|c|c|}
\hline $\begin{array}{c}\text { Question } \\
\text { number }\end{array}$ & $\begin{array}{c}\text { Number of } \\
\text { respondents }\end{array}$ & $\begin{array}{c}\text { Mean } \\
\text { value }\end{array}$ & $\begin{array}{c}\text { The standard } \\
\text { deviation }\end{array}$ & t-Value & $\begin{array}{c}\text { Degrees of } \\
\text { freedom }\end{array}$ & $\begin{array}{c}\text { Statistical } \\
\text { significance } \\
\alpha\end{array}$ \\
\hline Q18 & 20 & 2.65 & 1.089 & 10.878 & 19 & 0.05 \\
\cline { 1 - 1 } & 20 & 2.30 & 0.979 & 10.510 & 19 & 0.05 \\
\hline
\end{tabular}

Table- 5 Statistical Analysis of questions 29 and 30

\begin{tabular}{|c|c|c|c|c|c|c|}
\hline $\begin{array}{c}\text { Question } \\
\text { number }\end{array}$ & $\begin{array}{c}\text { Number of } \\
\text { respondents }\end{array}$ & $\begin{array}{c}\text { Mean } \\
\text { value }\end{array}$ & $\begin{array}{c}\text { The } \\
\text { standard } \\
\text { deviation }\end{array}$ & $\begin{array}{c}\text { calculated } \\
\text { t-Value }\end{array}$ & $\begin{array}{c}\text { Degrees of } \\
\text { freedom }\end{array}$ & $\begin{array}{c}\text { Statistical } \\
\text { significance } \\
\alpha\end{array}$ \\
\hline Q29 & 20 & 2.80 & 1.152 & 10.873 & 19 & 0.05 \\
\cline { 1 - 1 } & 20 & 2.15 & 0.813 & 11.831 & 19 & 0.05 \\
\hline
\end{tabular}

Table- 6 Statistical Analysis of questions 44 and 45

\begin{tabular}{|c|c|c|c|c|c|c|}
\hline $\begin{array}{c}\text { Question } \\
\text { number }\end{array}$ & $\begin{array}{c}\text { Number of } \\
\text { respondents }\end{array}$ & Mean value & $\begin{array}{c}\text { The standard } \\
\text { deviation }\end{array}$ & $\begin{array}{c}\text { calculated } \\
\text { t-Value }\end{array}$ & $\begin{array}{c}\text { Degrees of } \\
\text { freedom }\end{array}$ & $\begin{array}{c}\text { Statistical } \\
\text { significance } \\
\alpha\end{array}$ \\
\hline Q44 & 20 & 2.25 & 1.020 & 9.869 & 19 & 0.05 \\
\cline { 1 - 1 } & 20 & 2.15 & 1.040 & 9.245 & 19 & 0.05 \\
\hline
\end{tabular}

\section{Conclusion}

Based on statistical analysis above the following main points can be drawn:-

1. There is a clear desire for electrical power and water sectors in favor of application of TQM and Kaizen philosophies for quality management certificates as it was clear answers in this regard that reached above $70 \%$.

2. There is a large consensus by employees in the electricity and water sectors application of these philosophies will effectively contributes to reduce costs and expenses.

3. The application of total quality management and Kaizen methods affect efficiently the way the electricity sector and water maintenance management. 
4. Profits can be obtained when the application of TQM and Kaizen in the electricity and water sectors by improving the customer satisfaction and improve the performance of suppliers.

5. Results have shown a successful quality improvement accounted for over $75 \%$ in the electricity and water sectors.

6. Preferably working in the electricity and water application of TQM philosophy more than the application of the philosophy of kaizen.

7. During the period of the application of TQM and Kaizen on the electricity and water sectors there are a consensus that workers need to be trained on this new management.

8. Also there was a big difference in achieving customer satisfaction before and after the application of total quality management and Kaizen in the electricity and water sectors.

9. There is a big difference in profit before and after the application of total quality management and Kaizen in the electricity and water for the same period.

10. Answers varied between total quality management and Kaizen philosophies whether there is a need to increase the number of workers in the electricity and water sectors after a permanent application of these philosophies for more and continuous improvements.

\section{References:}

Hongyi Sun and Tsz-kit, 2002,"Comparing Reasons, Practices and Effects of ISO 9000

Certification and TQM Implementation in Norwegian SMEs and Large Firms"

Nawar Khan, 2006,"The Role of Culture in Successful Implementation of Quality Initiative"

Smans, G. VerElst, QualitéAssurée, VIF Editions, 2010,"Total Quality Management TQM"

Tauseef Aized, 2012,"Total Quality Management and Six Sigma"

Melsa, J.L, 2010,"Principals and tools of total quality management"

Jack P. Pekar . 1995,"Total Quality Management: Guiding Principles for Application"

Lakhe R. and Mohanty R.P., 1993,"Total Quality Management Concepts, Evolution and Acceptability to Develop Economies"

Salman D. Al-Shobaki a, Rami H. Fouad and Adnan Al-Bashir B., 2010,"The

Implementation of Total Quality Management (TQM) for the Banking Sector in Jordan" Martínez R. Lorente, 2009,"Total Quality Management: Origins and Evolution of the Term" 
Phu Van Ho, 2011,"Total Quality Management Approach to the Information Systems Development Processes: An Empirical Study".

John S. Oakland, 2003,"Total Quality Management text with cases"

Edward Sallis, 2002,"Total Quality Management in Education"

Carolin Richter, 2001,"The Application of Total Quality Management to NMHSs in Developing Counties"

Jacqueline Coyle-Shapiro, 1996,"The impact of a TQM intervention on work attitudes: a Longitudinal"

Thomas C.Powell, 1995,"Total Quality Management as competitive Advantage: A Review and Empirical study"

Slobodan Prošić, 2011,"Kaizen Management Philosophy"

Kai \& Zen, 2006, "Kaizen Definition \& Principles in Brief"

Mihail Aurel Titu; Constantin Oprean and Daniel Grecu , 2011,"Applying the Kaizen Method and the 5S Technique in the Activity of Post-Sale Services in the Knowledge-Based Organization"

Gratiela Dana BOCA, 2011,"Kaizen Method In Production Management"

Grips H., Development Forum, 2009,"Introducing Kaizen in Africa"

Koichi Shimizu, 2011,"Transforming Kaizen at Toyota"

Scott Rood voets, 2004,"Kaizen Improvement Systems Module"

Cristiana BOGDĂNOIU, 2009,"Business Process Reengineering Method versus Kaizen Method"

Jagdeep Singh* and Harwinder Singh, 2010,"Kaizen Philosophy: A Review of Literature" 